\title{
Gradhiva
}

GRADHIV

Revue d'anthropologie et d'histoire des arts

$4 \mid 2006$

Le commerce des cultures

\section{Bernard Juillerat, In memoriam}

\section{Christian Coiffier}

\section{OpenEdition}

\section{Journals}

Édition électronique

URL : http://journals.openedition.org/gradhiva/564

DOI : 10.4000/gradhiva.564

ISSN : 1760-849X

\section{Éditeur}

Musée du quai Branly Jacques Chirac

\section{Édition imprimée}

Date de publication : 1 novembre 2006

Pagination : 124

ISBN : 2-915133-44-1

ISSN : 0764-8928

Référence électronique

Christian Coiffier, «Bernard Juillerat, In memoriam », Gradhiva [En ligne], 4 | 2006, mis en ligne le 10 décembre 2008, consulté le 15 septembre 2020. URL : http://journals.openedition.org/gradhiva/564

Ce document a été généré automatiquement le 15 septembre 2020.

(c) musée du quai Branly 


\title{
Bernard Juillerat, In memoriam
}

\author{
Christian Coiffier
}

1 Bernard Juillerat est décédé le 8 juin 2006, quelques jours avant l'ouverture du musée du quai Branly. Son œuvre demeure éminemment présente dans cette institution à travers ses ouvrages, ses photographies et ses films conservés à la médiathèque. Les réserves recèlent plusieurs centaines d'objets ethnographiques qu'il avait rapportés de ses diverses missions en Papouasie-Nouvelle-Guinée. Parmi ceux-ci, certains masques de danse, constitués de peintures sur spathes de palmier, peuvent être considérés comme de véritables œuvres d'art. La documentation de cette collection demeure exemplaire en ce qui concerne la précision et la qualité de la rédaction des diverses fiches d'objets illustrées pour chacune d'entre elles de photographies.

Bernard Juillerat, affaibli depuis quelques mois par une longue maladie, a disparu discrètement. Il venait de prendre sa retraite en tant que directeur de recherche au CNRS après une brillante carrière dévolue à l'anthropologie sociale. Il ne m'appartient pas de retracer celle-ci car d'autres sauront le faire mieux que moi. C'est en tant que secrétaire général de la Société des océanistes que j'ai proposé d'écrire ces quelques lignes en hommage à un collègue qui a profondément marqué mon parcours personnel et dont nous étions nombreux à apprécier la grande rigueur scientifique. Bernard Juillerat assura très consciencieusement les fonctions de secrétaire général adjoint responsable du JSO (Journal de la Société des océanistes) de 1977 à 1982. Il donna alors à cette revue un caractère plus international en publiant de nombreux articles de collègues anglo-saxons. Il écrivit d'ailleurs lui-même divers articles et comptes rendus dans cette revue.

D'origine helvétique, Bernard Juillerat s'est orienté vers l'ethnologie après des études de lettres et de philosophie. C'est en Afrique, au Nord-Cameroun, qu'il effectua ses premières recherches chez les Mouktélé et qu'il publia son premier ouvrage en 1971 à partir de sa thèse de doctorat. Il décida alors de choisir un autre terrain en PapouasieNouvelle-Guinée, chez les Yafar du district d'Amanab dans la province du Sépik occidental, proche de la société umeda étudiée précédemment par Alfred Gell. Outre de très nombreux articles dans diverses revues scientifiques comme L'Homme, Man, Diogène, JSO, Baeesler Archiv, Revue française de psychanalyse, etc., Bernard Juillerat fit 
paraître sur la société yafar trois ouvrages personnels. Le premier, Les Enfants du sang, gros volume de 570 pages publié en 1986 par la Fondation de la Maison des sciences de l'homme, est le résultat d'une quinzaine d'années de recherche dont trois passées sur le terrain. Cette monumentale monographie présente de façon magistrale comment un peuple d'horticulteurs-chasseurs forestiers, les Yafar, a élaboré sa propre culture par l'inscription de catégories sociales en profonde symbiose avec la nature environnante. À partir d'une conséquente documentation ethnographique, l'auteur présente diverses interprétations de la vie économique, sociale et rituelle qui font de cet ouvrage un travail exemplaire pour les jeunes générations d'ethnologues. Les deux ouvrages suivants, L'Avènement du père et đEdipe chasseur,publiés respectivement en 1991 aux Éditions du CNRS-Maison des sciences de l'homme et en 1995 aux Presses Universitaires de France, sont la marque de la spécificité et de l'évolution des recherches effectuées par Bernard Juillerat car ils présentent tous deux une analyse ethnographique rigoureuse associée à une réflexion inspirée par la psychanalyse freudienne. L'ouvrage collectif Shooting the Sun, publié en 1992 par la Smithsonian Institution Press, fut réalisé en collaboration avec divers collègues anthropologues et psychanalystes comme une réflexion théorique autour du rituel ida des Umeda décrit par Alfred Gell. Bernard Juillerat participa également à divers ouvrages collectifs comme Big Men and Great Men, dirigé par Maurice Godelier et Marilyn Strathern et Peoples and Things, qu'il a codirigé avec Monique Jeudy-Ballini. En 1993, il publia également aux éditions du CNRS, La Révocation des Tambaran, fruit d'une mission de trois mois chez les Banaro, peuple vivant sur les bords du haut Keram, affluent du fleuve Sépik, et étudié au début du Xx siècle par l'ethnologue allemand Richard Thurnwald. Il constate amèrement qu'il lui est totalement impossible d'identifier les vestiges des institutions décrites par l'ethnologue berlinois, ses informateurs banaro ne pouvant même pas reconnaître leur propre culture au travers de ces descriptions. Bernard Juillerat était un homme modeste, sensible et secret. Il laissait très difficilement paraître ses sentiments. Mais cette sensibilité transparaissait fort bien dans ses très esthétiques photographies et dans son film désormais fameux, Le Sang du sagou, réalisé avec l'aide du CNRS. Il n'était pas homme à se mettre en avant, mais il avait le souci d'assumer ses responsabilités puisqu'il dirigea pendant plusieurs années le GDR $116 \mathrm{du}$ CNRS "Identité et transformations des sociétés océaniennes ".

4 Le décès de Bernard Juillerat a suscité une vive émotion en Papouasie, où celui-ci était bien connu par ses collègues universitaires papous et anglo-saxons. Le peuple yafar a perdu un ami qui avait su transmettre en Occident les valeurs et les principes les plus intimes de leur société. L'Alliance française de Port Moresby souhaiterait honorer son œuvre par une petite publication bilingue et éventuellement par une exposition. Lors de sa dernière assemblée générale du mois de juin, la Société des océanistes a décidé, à la requête de son président Maurice Godelier, d'organiser dans le courant de l'année 2007 une journée en hommage à l'œuvre de Bernard Juillerat. Cette journée pourrait être coordonnée avec la manifestation souhaitée en Papouasie-Nouvelle-Guinée. Ce serait l'occasion pour ceux et celles qui ont connu et apprécié Bernard Juillerat de manifester leur reconnaissance envers les apports de celui-ci aux sciences sociales. 


\section{AUTEUR}

\section{CHRISTIAN COIFFIER}

christian.coiffier@quaibranly.fr 